\title{
Cost-Benefit Investigation of Offshore Wind Power Generation for Soroush Offshore Complex
}

\author{
Shahab Shahriari ${ }^{1}$, Pedram Edalat ${ }^{2 *}$, Gholam reza Salehi $^{3}$ \\ ${ }^{I}$ M.Sc. Student at Energy Systems Engineering, Petroleum University of Technology; sh.shahriari@mnc.put.ac.ir \\ ${ }^{2}$ Assistant Professor, Petroleum University of Technology; edalat@put.ac.ir \\ ${ }^{3}$ Assistant Professor, Petroleum University of Technology; Gh.salehi@put.ac.ir
}

\section{ARTICLE INFO}

Article History:

Received: 15 May. 2017

Accepted: 27 Sep. 2017

Keywords:

Soroush oilfield,

Renewable energy,

wind power,

environmental pollution,

The Persian Gulf

\begin{abstract}
Iranian offshore oil and gas platforms are mostly located in the Persian Gulf. Technical and environmental challenges resulted from an off-design running condition of processes on a platform are important issues. The weakness of strategies to stop or decrease the amount of greenhouse gas emission production rate in the Persian Gulf; which is intensively increasing, is another matter of concern. modern methods of energy generation from available renewable potentials near offshore platforms are suggested. Integration of renewable energy converters with offshore oil and gas platforms can solve both problems with machinery and environment to an acceptable extent. In this study, the economics of the Soroush offshore complex is subjected to two scenarios. The first scenario defines the present condition in which the total power demand of the complex is supplied by burning the associated extracted natural gas on board the platform in its thermal power plant and the second scenario considers a wind farm located near Bardekhun in Bushehr province to be connected to the complex power network and shares its renewable source generated power with the platform. The economics of both scenarios are compared in terms of total annual power cost. The second scenario shows more beneficial, although there are some conservative assumptions included due to a shortage of data and limitations.
\end{abstract}

\section{Introduction}

The offshore power production is mainly based on the use of gas or diesel turbines with an efficiency that is quite low ( 20-25\%) [1]. As a typical solution; mounting diesel or gas turbine generators on platforms or barges introduces its own issues. These generators are difficult to maintain and operate at sea. Diesel generators must be refueled frequently, requiring costly logistics such as ship trips. Gas turbine generators also burn the fuel gas which is produced on the platform. this fuel could be exported to the pipeline and make money instead of being burnt. The cost of the fuel itself is extravagant, especially for longer-term operations. Further, diesel generators emit $\mathrm{CO}_{2}$ which can affect operations via environmental regulations [2]. As an example for Norway, continuous burning of these conventional fuels in offshore generators will generate about $80 \%$ of the total $\mathrm{CO}_{2}$ and $\mathrm{NO}_{\mathrm{x}}$ emissions from the Norwegian offshore installations. Thus, offshore platforms are facing difficulties in term of operating their activities in an environmental manner [3].
Recently, growing global tendency to eliminate or lower emission production by application of green power generation methods has caused Newer and less ecologically harmful technologies to be developed in order to generate power on offshore platforms not only renewable but also pollution-free [4]. Generally, there are lots of studies done in the field of obtaining renewable energies from stochastic natural energy potentials, optimizing the energy absorbing modules for offshore and onshore environments and integrating harvested green energies with conventional energy systems worldwide. Among these, only a few are concerned with the energy system of an offshore oil \& gas platform.

Eriksson et al. in 2008 made a comparative study of three different wind turbine concepts including Horizontal axis wind turbine (HAWT) and two different concepts of vertical axis wind turbines (VAWTs); the Darrieus turbine and the H-rotor, from the most important aspects including structural dynamics, control systems, maintenance, manufacturing and electrical equipment. They 
concluded that the VAWTs appear to be advantageous to the HAWTs in several aspects [5]. In 2011, Offshore Renewable Energy Conversion platforms Coordination Action (ORECCA) reported the inventory of the state of the art of current renewable energy converters and platform technologies as they are being used in the oil and gas industry, offshore wind energy industry and the ocean energy, i.e. the wave and tidal energy as well as a benchmark among different technologies on the basis of the experience of the partners of their projects. This report developed the criteria to identify the benefits and limits of each type of structure, also the applicability of the structures for offshore renewable technologies in a comparative study [6]. In 2012, Aslam bhutta et al. also compared the differences between VAWTs; newly developed concept; and conventional proved HAWT ones, mentioning their considerable advantageous such as not being depended to the direction of the wind, no need to install any room above the tower to space generator and gears, simpler tower construction and installation along with lower capital and operational costs. They also introduced VAWTs as the promising solution for areas away from the integrated grid systems which can offer a solution to the energy requirements ranging from $2 \mathrm{~kW}$ to $4 \mathrm{MW}$ with a reasonable payback period [7]. Figure 1 shows a schematic of mentioned wind turbines.

$\mathrm{Hj}$ Mohd Amin in 2014, discussed the application of various sources of alternative energy to assist with powering of offshore oil platforms particularly, the one that is located on North West Shelf of Australia. Wind, wave, and solar were investigated. He also performed the optimization of feature selections before choosing the most suitable device for each energy resource. By comparing the capital cost required for each type of commercial energy converters, the most suitable option is introduced. From the findings of this study; for the considered platform demanding $30 \mathrm{MW}$ power, the available options would be utilizing 40 units of Pelamis type, 35 units of PowerBouy type and 86 units of Wave dragon type wave energy converters (WECs), each unit with a rated power capacity of 750,866 and $350 \mathrm{~kW}$ respectively, with a capital cost of 1.2-1.8 million USD, if wave energy alone is considered to supply the whole platform. 15 units of Vestas V80-2MW with a capital cost of 2 million USD, would be the best solution among other offshore wind turbines if wind energy is subjected alone. He also mentioned that solar energy source is not a good choice for powering offshore platform due to the high cost of installation and maintenance [8]. It has not been considered the inherent stochastic nature of the wind and wave energy in the outcomes of the total generated power in a study done by Hj mohd Amin.

Recent developments in renewable energy technologies have extensively decreased the price for each unit of generated power as well as diminishing the greenhouse gas emission production. Integration of renewable energy converters with offshore oil and gas platforms will solve both problems with machinery off-design running condition consequences and maintenance costs and environmental issues to an acceptable extent. The integrated platform would be able to sell its extra generated power to its neighbor platforms or to the shore via cables [9]. This study aims to consider wind potentials of the Persian Gulf to supply the electricity demands of Soroush offshore complex. The stochastic nature of the winds being converted to generate power using HAWT farm installed in a location near the considered Iranian
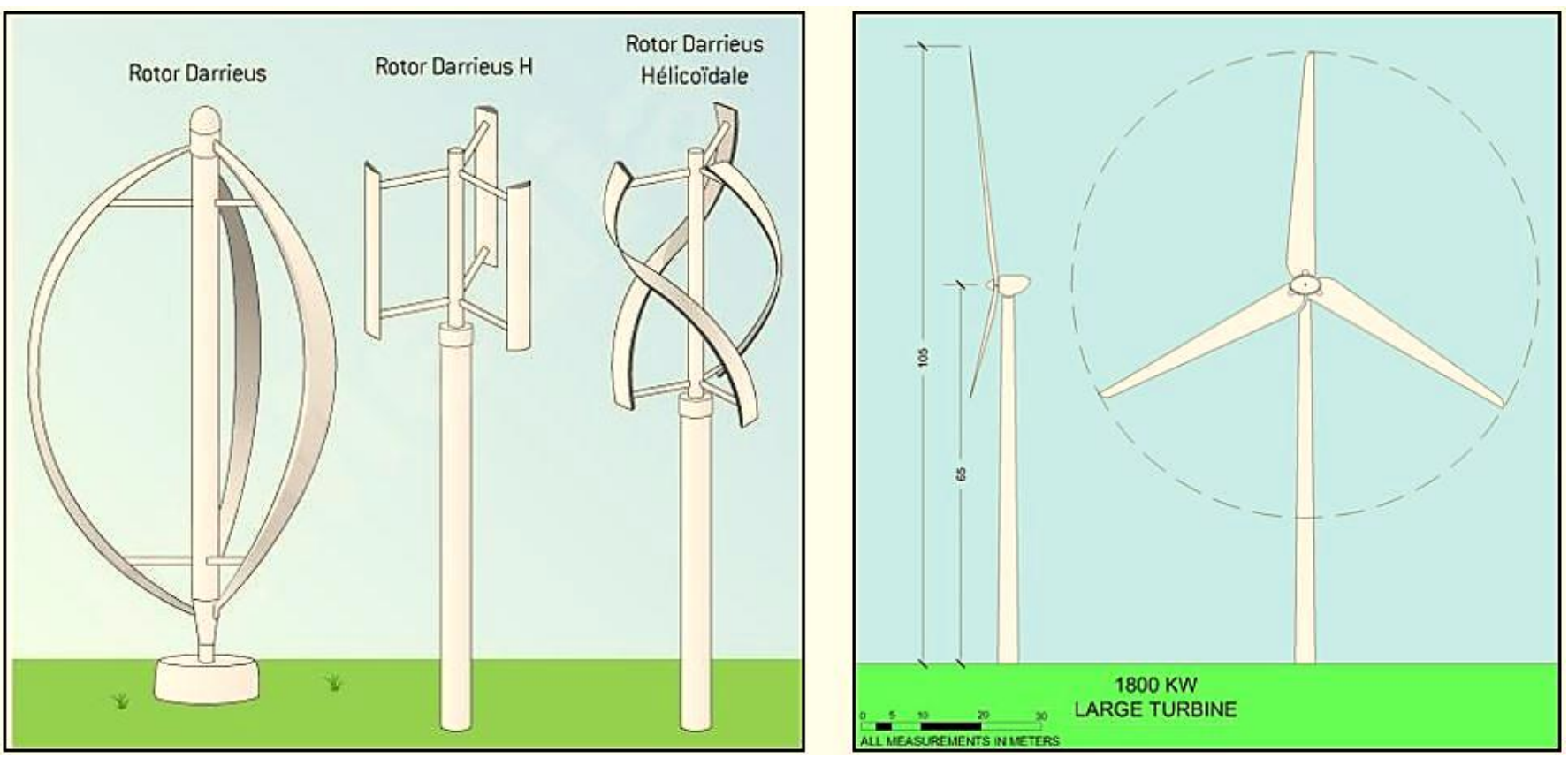

Figure 1 VAWT and HAWT schematic overview 
offshore platform is also considered. The present study compares the economics of both normal gas turbine and recommended hybrid configuration (wind turbines and the onboard gas turbines).

\section{Soroush Complex}

Soroush complex is located $85 \mathrm{~km}$ off southwest of kharg Island in the Persian Gulf. As shown in Figure 2, It contains 5 platforms; two production platforms (SPP-1 and SPP-2), 2 wellhead platforms (SWP-1 and SWP-2), one living quarter (SLQ) plus a Floating Storage Unit (FSU). The production facilities of the Soroush field (SPP-1 and SPP-2) will allow for crude treatment to export specification, prior to transfer to the FSU. SPP-2 is a dedicated platform for the final processing of the crude oil coming from nearby Nowrooz field and export to the storage facility. The Soroush crude is processed on its dedicated platform, SPP-1.

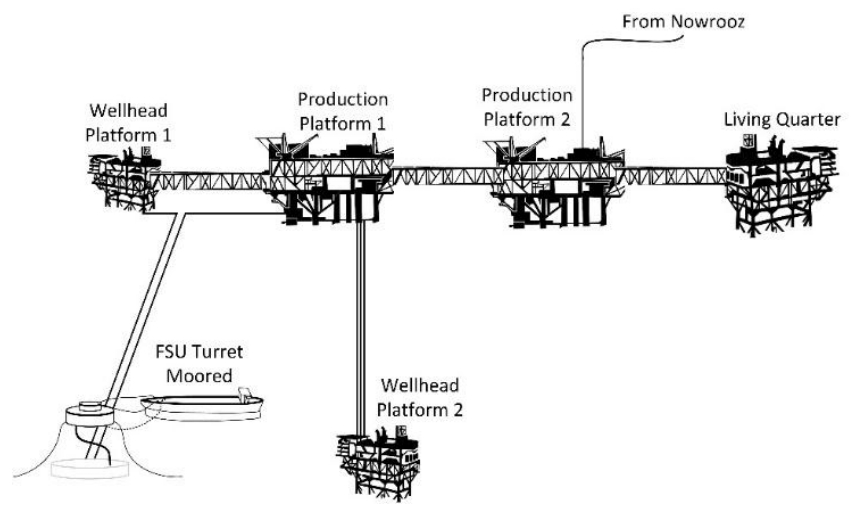

Figure 2 Soroush field overview

The complex is equipped with a thermal plant consisting Natural Gas Turbine generators (NGT) (3 sets, each one 13.07 MW) which are designed in a way to supply total estimated platform electricity and process heating demands in both normal and peak load conditions. Load conditions are forecasted from the primary relevant reservoir studies and analyses. These demands are supplied by burning associated extracted natural gas from the field itself and diesel in the case of emergencies. There are two different electricity switchboards connected to the Soroush electricity network which are high $(11 \mathrm{kV})$ and normal $(400 \mathrm{~V})$ load switchboards. There is another $400 \mathrm{~V}$ switchboard installed on platforms as an emergency switchboard that is directly connected to diesel generators to take responsibility of the power distribution in the case of emergencies in order not to shut down the critically essential machinery or processes on the platforms. Table 1 lists the demand details in both normal and peak load conditions for each platform.

To calculate the cost of the fuel required on the complex to fulfil its demand in peak load conditions and to have an estimation of the complex power demand behavior in time, it is considered that the NGTs take full load (100\%) of 33.637 MW for 16 hours per day, medium load (70\%) of $23.5459 \mathrm{MW}$ for 4 hours per day, and minimum load $(50 \%)$ of 16.8185 MW for 4 hours per day.

Table 1 Power demand listed by platform and switchboard [10].

\begin{tabular}{|c|c|c|c|c|c|c|c|}
\cline { 3 - 8 } \multicolumn{2}{c}{} & \multicolumn{3}{c}{ Normal } & \multicolumn{3}{c|}{ Peak } \\
\hline \multirow{2}{*}{ Platform } & $\begin{array}{c}\text { Voltage } \\
(\mathrm{V})\end{array}$ & $\mathrm{kW}$ & $\mathrm{kVAr}$ & $\mathrm{kVA}$ & $\mathrm{kW}$ & $\mathrm{kVAr}$ & $\mathrm{kVA}$ \\
\hline \multirow{3}{*}{ SPP-1 } & $11 \mathrm{k}$ & 21993 & 14133 & 26142 & 22720 & 14521 & 26964 \\
\cline { 2 - 8 } & 400 & 1264 & 1094 & 1672 & 1366 & 1154 & 1788 \\
\cline { 2 - 8 } & 400 & 662 & 415 & 781 & 695 & 435 & 820 \\
\hline \multirow{3}{*}{ SWP-1 } & 400 & 60 & 35 & 69 & 68 & 40 & 79 \\
\cline { 2 - 9 } & 400 & 16 & 8 & 18 & 18 & 10 & 21 \\
\hline \multirow{3}{*}{ SWP-2 } & $11 \mathrm{k}$ & 1697 & 1692 & 2396 & 1706 & 1698 & 2407 \\
\cline { 2 - 9 } & 400 & 93 & 57 & 109 & 102 & 63 & 120 \\
\hline \multirow{3}{*}{ SLQ } & 400 & 938 & 545 & 1085 & 963 & 561 & 1114 \\
\cline { 2 - 8 } & 400 & 269 & 169 & 317 & 285 & 179 & 336 \\
\hline \multirow{3}{*}{ SPP-2 } & $11 \mathrm{k}$ & 4406 & 2916 & 5284 & 4600 & 3032 & 5509 \\
\cline { 2 - 8 } & 400 & 910 & 870 & 1259 & 969 & 904 & 1325 \\
\cline { 2 - 8 } & 400 & 139 & 87 & 164 & 145 & 91 & 171 \\
\hline \multicolumn{2}{|c|}{ Total Demand } & 32447 & 22021 & 39296 & 33637 & 22688 & 40654 \\
\hline
\end{tabular}

From the available data for a similar platform design by SHELL, considering a year in hours, the full load $(100 \%)$ represents $2 / 3$ of the time $(=5840 \mathrm{hrs})$, both the medium load $(70 \%)$ and the minimum load $(50 \%)$ represent $1 / 6$ of the time $(=1460 \mathrm{hrs})$ [11]. Considered scheduled daily normal consumption is: $24-10 \mathrm{hrs}$ 100\% Load, 11-14hrs 70\% Load, 15-19hrs 100\%

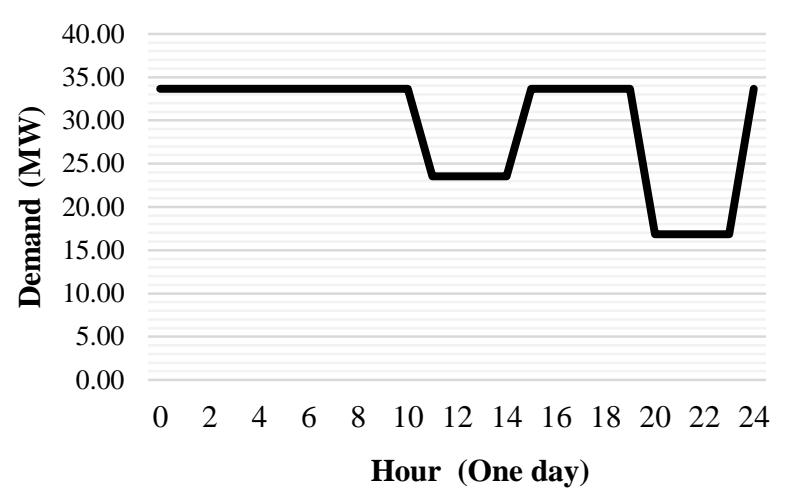

Figure 3 Soroush considered daily power demand pattern

Load, 20-23hrs 50\% Load. The energy efficiency of the natural gas turbine system is assumed to be $20 \%$. Figure 3 shows the total power demand in hours for a day. the energy content of natural gas is assumed to be $1031 \mathrm{BTU} / \mathrm{ft} 3$. using equation 1 , knowing the price of NG it is converted to USD/kWh [11]. This data will be used for estimations of the cost of natural gas required to generate the needed power output. Table 2 shows the total annual fuel cost on Soroush and means that this capacity is burned in the thermal plant to produce power instead of being exported and making the same income.

Fuel Cost (Natural Gas) $=$

$\frac{2.53 U S D}{1 e 6 \mathrm{Btu}} \times \frac{3412 \mathrm{Btu}}{1 \mathrm{kWh}} \times \frac{100}{20}=0.04 \frac{U S D}{k W h}$ 
Table 2 Soroush annual fuel cost

Natural Gas Price = 0.04 USD/kWh [11]

\begin{tabular}{|c|c|c|c|c|}
\hline 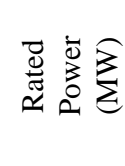 & 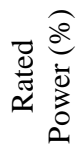 & 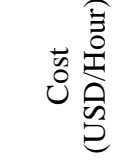 & 墨 & 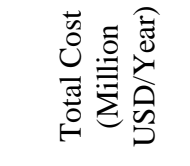 \\
\hline 33.637 & 100 & $1,345.48$ & 5840 & $7,857,603.20$ \\
\hline 23.5459 & 70 & 941.84 & 1460 & $1,375,080.56$ \\
\hline 16.8185 & 50 & 672.74 & 1460 & $982,200.40$ \\
\hline \multicolumn{4}{|c|}{ One Year Fuel Cost } & $10,214,884.16$ \\
\hline
\end{tabular}

\section{Persian Gulf Wind Potential}

Bardekhun is located in the vicinity of Deyer port in Bushehr province in the coasts of Persian Gulf. It is situated in the latitude of $27^{\circ} 98^{\prime} \mathrm{N}$, the longitude of $51^{\circ} 49^{\prime} \mathrm{W}$ and the altitude of $4 \mathrm{~m}$. A dominating wind in this region is North Wind which has an effect on the architectural and environmental design of buildings. The one-year measured hourly time-series wind speed data, from January 1, 2007, to December 31, 2007, are extracted from Renewable Energy Organization of Iran (SUNA) [12]. Figure 4 shows the monthly average wind speed at Bardekhun station recorded in three different heights; $10 \mathrm{~m}, 30 \mathrm{~m}$, and $40 \mathrm{~m}$.

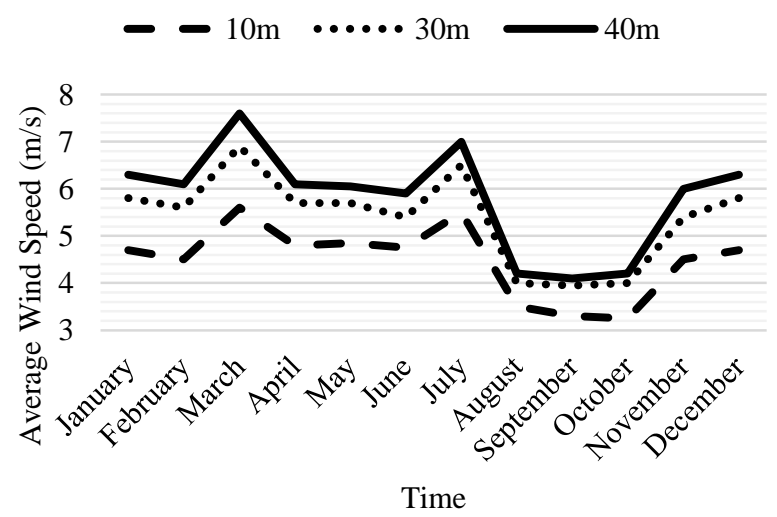

Figure 4 Monthly average wind speed at Bardekhun station [13]

Generally, Rayleigh and Weibull distributions are used for wind data analysis, Equation 2. $\mathrm{U}$ is the wind speed and $\mathrm{K}$ and $\mathrm{C}$ are the constants used for Rayleigh distribution which are calculated for three different heights and are listed in table 3 . Figure 5 shows the Rayleigh distribution of the wind speed at three different heights in Bardekhun wind station.

$$
\begin{aligned}
& p(U)=\left(\frac{k}{c}\right)\left(\frac{U}{c}\right)^{k-1} \exp \left[-\left(\frac{U}{c}\right)^{k}\right] \\
& F(U)=1-\exp \left[-\left(\frac{U}{c}\right)^{k}\right] \\
& k=\left(\frac{\sigma_{U}}{\bar{U}}\right)^{-1.086}, \frac{c}{\bar{U}}=\frac{k^{2.6674}}{0.184+0.816 k^{2.73855}}
\end{aligned}
$$

Table 3 Rayleigh inputs and Constants

\begin{tabular}{cccc} 
& $10 \mathrm{~m}$ & $30 \mathrm{~m}$ & $40 \mathrm{~m}$ \\
\hline $\mathrm{U}$ mean $(\mathrm{m} / \mathrm{s})$ & 4.5 & 5.36 & 5.83 \\
\hline Std. Dev. & 4.506 & 3.042 & 3.313 \\
\hline $\mathrm{k}$ & 1.737 & 1.85 & 1.848 \\
\hline $\mathrm{c}$ & 5.058 & 6.037 & 6.568 \\
\hline
\end{tabular}

To obtain the annual amount of available harvested energy from Bardekhun station, Siemens 3.6 MW wind turbine (SWT 3.6MW) with a tower of $90 \mathrm{~m}$ tall and blade diameter of $120 \mathrm{~m}$ is considered [14]. The mean wind speed at height $90 \mathrm{~m}$ is absolutely higher compared with the available data at $60 \mathrm{~m}$ height. So, obtained energy calculated this way would be acceptably conservative. from Figure 5, which shows the power curve for the SWT 3.6 MW; the turbine cut in and cut out speed is respectively $3.8 \mathrm{~m} / \mathrm{s}$ and 25 $\mathrm{m} / \mathrm{s}$. the turbine reaches its rated power when the wind speed is $13 \mathrm{~m} / \mathrm{s}$. The mean annual amount of nominal

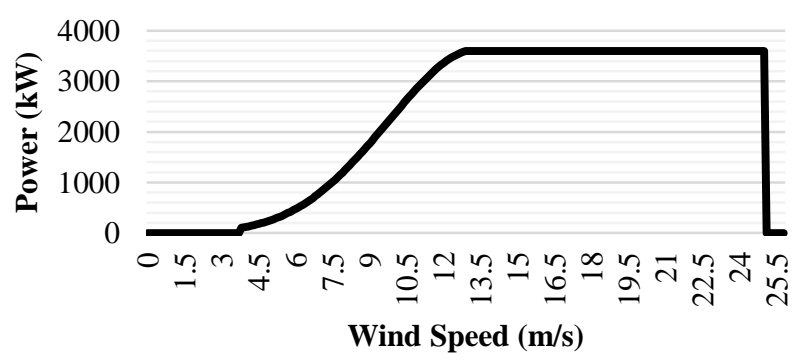

Figure 6 SWT 3.6 MW power curve [14]

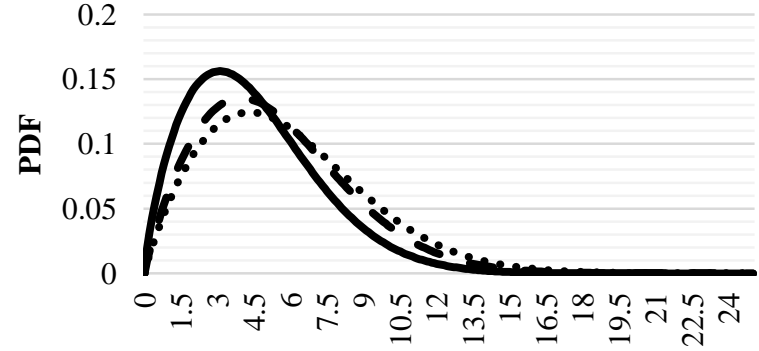

Wind Speed $(\mathrm{m} / \mathrm{s})$

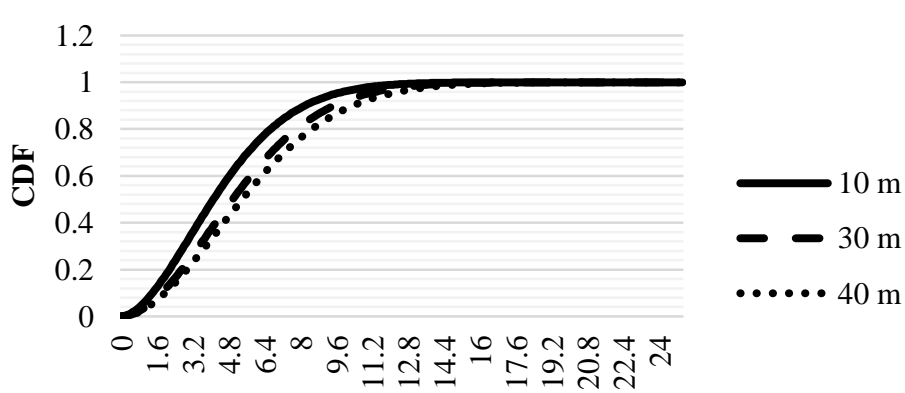

Wind Speed $(\mathrm{m} / \mathrm{s})$ 
Figure 5 Wind speed Rayleigh distribution in a year

power generated by a wind turbine with a given power curve $\mathrm{Pw}(\mathrm{U})$ for nominal wind speeds $\mathrm{U}$ is calculated using Equation 3 [14]:

$$
\begin{aligned}
\overline{P_{w}} & =365 \times 24 \int_{0}^{\infty} p(U) P_{w}(U) \\
& =365 \times 24 \times \sum_{i=1}^{N_{B}} \frac{1}{2}\left(U_{i+1}-U_{i}\right)\left(p\left(U_{i+1}\right) P_{w}\left(U_{i+1}\right)+p\left(U_{i}\right) P_{w}\left(U_{i}\right)\right)
\end{aligned}
$$

\section{Results}

Equation 3 gives the total mean amount of possible power generation with considered wind turbine if being installed at Bardekhun station as listed in table 4. Knowing the average wind speed in time; it is possible to estimate how much the power is generated in time during a year. Here the only available data is the wind speed monthly average at a height of $40 \mathrm{~m}$ over Bardekhun station. Figure 7 shows the resulted monthly average power generated by an SWT 3.6 MW considered to be installed there, using lower level wind data. It is obvious that the turbine has its least generation period in August, September, and October because the average wind speed hardly passes the turbines cut in speed; as is shown in Figure 7.

Table 4 Mean annual power generation of an SWT 3.6 MW at Bardekhun station

\begin{tabular}{cc}
\hline Site & Bardekhun \\
\hline Turbine height & $90 \mathrm{~m}$ \\
\hline $\begin{array}{c}\text { Mean wind speed } \\
(40 \mathrm{~m} \text { wind data })\end{array}$ & $5.83 \mathrm{~m} / \mathrm{s}$ \\
\hline Turbine type & SWT $3.6 \mathrm{MW}$ \\
\hline Cut in speed & $3.8 \mathrm{~m} / \mathrm{s}$ \\
\hline Cut off speed & $25 \mathrm{~m} / \mathrm{s}$ \\
\hline Rated speed & $13 \mathrm{~m} / \mathrm{s}$ \\
\hline Mean annual power generation & $6931.130 \mathrm{MW}$ \\
\hline
\end{tabular}

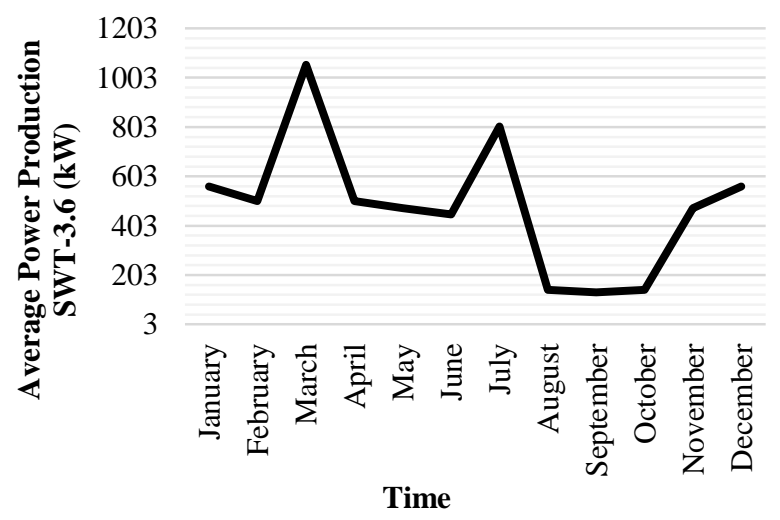

Figure 7 Monthly average generation of an SWT 3.6 MW

From the considered load power demand in time (Figure 3), the total demand of the complex is calculated in a year; bearing in mind that the fluctuations of the feed properties when entering the processes on platforms and aging of the field itself and the machinery cause off-design running conditions resulting continuous increase in the total Soroush complex power demand during its lifetime; mentioned fluctuations are neglected in a single year. Table 5 shows the minimum number of required SWT 3.6 MW to be installed in a wind farm at Bardekhun station which can generate as much power as the yearly demand of the complex in a year utilizing the wind potentials of the site.

Table 5 Number of required SWT 3.6 MW to be

\begin{tabular}{|c|c|c|c|c|c|}
\hline $\begin{array}{l}\text { Rated } \\
\text { Power } \\
(\mathrm{MW})\end{array}$ & $\begin{array}{c}33.63 \\
7\end{array}$ & 23.5459 & 16.8185 & $\begin{array}{c}\text { yearly } \\
\text { demand } \\
(\mathrm{MWh})\end{array}$ & 255372.104 \\
\hline $\begin{array}{l}\text { Time } \\
\text { (Hour/ } \\
\text { Year) }\end{array}$ & 5840 & 1460 & 1460 & $\begin{array}{c}\text { Required } \\
\text { number } \\
\text { of SWT } \\
3.6 \mathrm{MW}\end{array}$ & 37 \\
\hline
\end{tabular}
installed

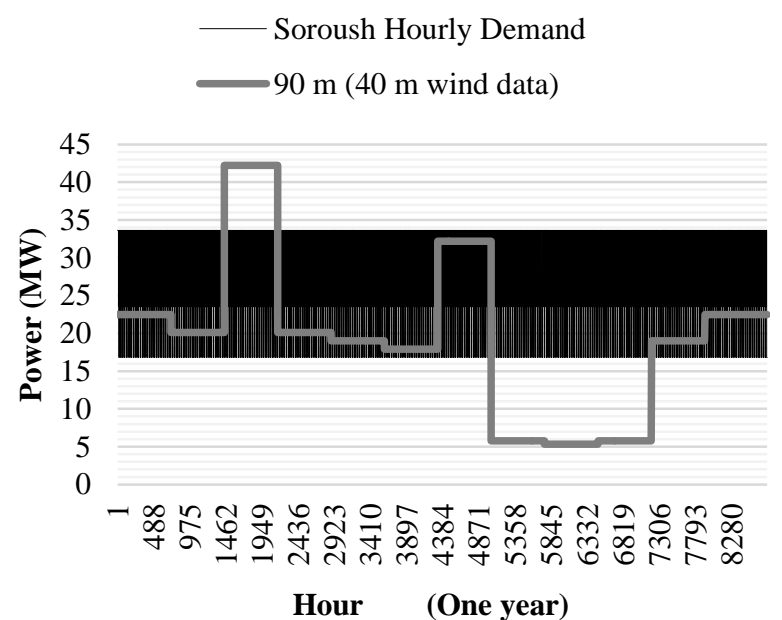

Figure 8 Wind power and the Soroush power demand in a year

Considering a wind farm consisting 40 SWT 3.6MW; in order to have a conservative number of turbines regarding the minimum required number of them which about 37; The average monthly amount of power generated is compared with the hourly average demand of the Soroush complex in a year, as is shown in Figure 8. Figure 9 shows the resultant demand for the complex, considering the farm is supplying a share of the total platform demand. positive resultant power means the demand for the complex is more than the amount of renewable power potential of the considered farm while negative resultant power shows the surplus of the renewable source generated power. This hybrid configuration requires $26 \mathrm{MW}$ power at the peak time which can be supplied by 2 sets of already 3 installed NGT installations. Lowering onboard required personnel, maintenance costs, burnt fuels and emissions at the peak condition are only some early results of the recommended configuration. 


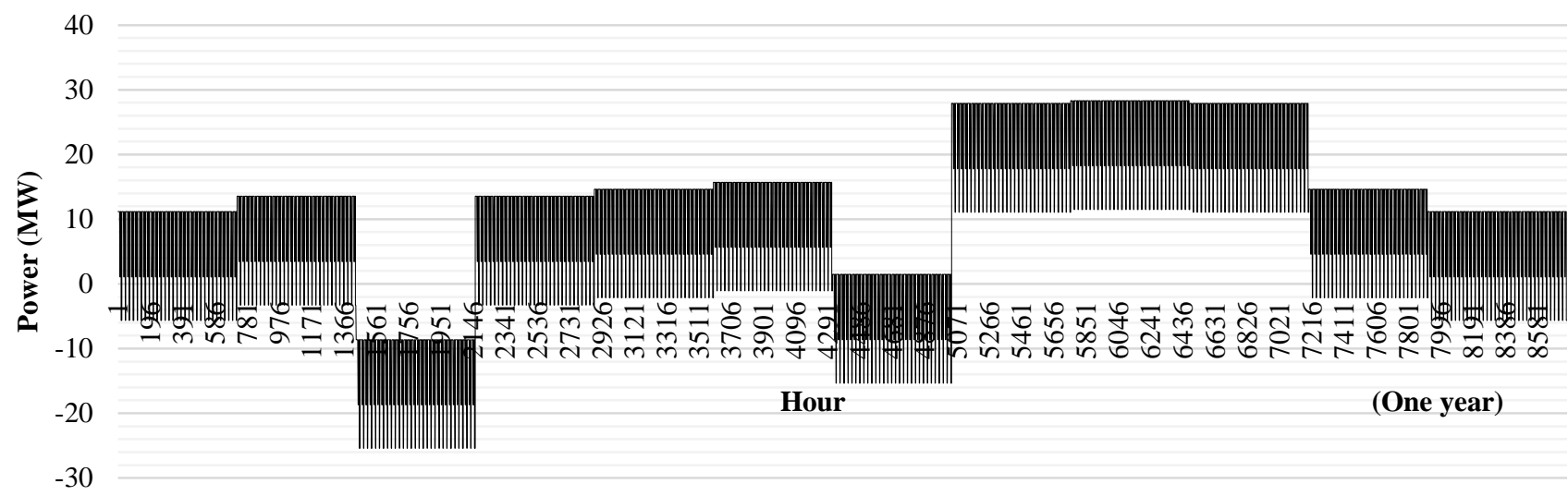

Figure 9 Renewable power surplus (-) and Fuel burned power required

There are some periods with a surplus of the renewable source generated power which can be sold to the local on land electricity network and make incomes for the complex. The selling guaranteed price for renewable source generated power is announced to be 89.47 (USD/MWh) by the Government [15].

The other option would be to store the excess power in high capacity batteries in order to be utilized in peak conditions, lowering the total demand, required maintenance and emission penalty costs as well.

Table 6 lists the total annual power costs for each scenario.

\section{Conclusion}

Considering the technical and environmental problems resulted from an off-design running condition of processes on a platform and the absence of any strategies to stop or decrease the amount of the greenhouse gas emission for these platforms. modern methods of energy generation from available renewable potentials near offshore platforms are suggested. Recent developments in renewable energy technologies have extensively decreased the price for each unit of the generated power as well as diminishing the greenhouse gas emission production.

Table 6 Normal (Scenario 1) and Hybrid configuration (Scenario 2) annual Soroush Complex Cost

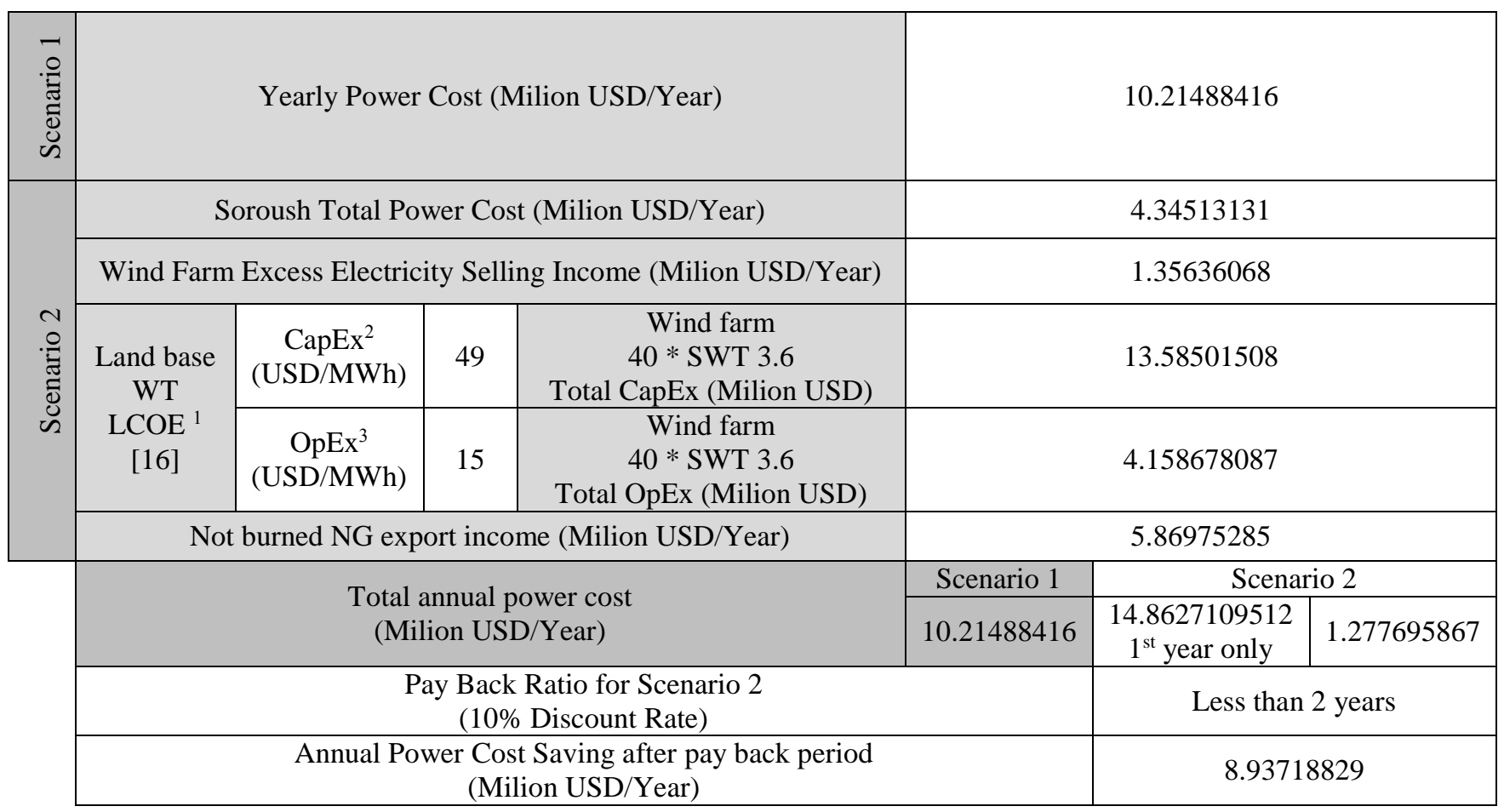

Levelised Cost of Energy

Capital Expenditures

Operational Expenditures 
Integration of renewable energy converters with offshore oil and gas platforms will solve both problems with machinery and environment to an acceptable extent. The integrated platform would be able to sell its extra generated power to its neighbor platforms or to the shore via cables. In this study, the economics of the Soroush offshore complex is subjected considering two scenarios. The first scenario defines the present condition in which the total power demand of the complex is supplied by burning the associated extracted natural gas on board the platform and the second scenario considers an imaginary wind farm consisting 40*SWT 3.6 MW located near Bardekhun in Bushehr province to be connected to the complex power network and shares its renewable source generated power with the platform. The second scenario shows considerably less annual power cost. Decreasing onboard NG combustion in thermal plants causes a decrease in annual emission production and financial penalties associated. Increasing the export rate of NG would be the other result as it is not burnt onboard at previous rates anymore. Considering the second scenario, after the lifetime of the offshore complex; the wells are plugged, platforms are abandoned but the wind farm continues its power generation, making absolute income for the owner company. The calculations done for renewable power generation in this study are based on HAWTs technology and their available experimental data, which are generally being used worldwide. Considering VAWTs technologies in future years, which are being discussed having more efficiencies and power output capacity in addition to lower operational and maintenance costs, increases the total cost difference between both scenarios and makes the second scenario more and more economically attractive.

\section{References}

1- Baringbing, J., Kandepu, R., Beyer, H.-G., Randeberg, E. and LundBo, O., (2011), Integration of fuel-based energy with offshore oil and gas installation with wind farms, main grids and other renewable energy systems, M.Sc Thesis, Stavanger.

2- Mekhiche, M. and Kathleen, A. E., (2014), A renewable energy source for powering offshore oil and gas applications, 19th Offshore Symposium, pp. 1-11.

3- Tiong, Y. K., Zahari, M. A., Wong, S. F. and Dol, S. S., (2015), The Feasibility of Wind and Solar Energy
Application for Oil and Gas Offshore Platform, Material Science Engineering, vol. 78, no. 12042. https://doi.org/10.1088/1757-899X/78/1/012042

4- Zahari, M. A. and Dol, S. S., (2014), Application of Vortex Induced Vibration Energy Generation Technologies to the Offshore Oil and Gas Platform: The Preliminary Study, International Journal of Mechanical, Aerospace, Industrial, Mechatronic and Manufacturing Engineering, vol. 8, no. 7, pp. 1321-1324.

5- Eriksson, S., Bernhoff, H. and Leijon, M., (2008), Evaluation of different turbine concepts for wind power, Renewable Sustainable Energy Review., vol. 12, no. 5, pp. 1419-1434, 2008.

https://doi.org/10.1016/j.rser.2006.05.017

6- Vannuci, D., (2011), WP3 technologies State of the Art.

7- M. M. Aslam Bhutta, N. Hayat, A. U. Farooq, Z. Ali, S.

R. Jamil, and Z. Hussain, (2012), Vertical axis wind turbine A review of various configurations and design techniques, Renewable Sustainable Energy Review, vol. 16, no. 4, pp. 1926-1939.

https://doi.org/10.1016/j.rser.2011.12.004

8- $\mathrm{Hj}$ Mohd Amin, M. F., (2014), Use of Alternative Energies in the Australian Offshore Sector, Australian maritme college.

9- Shahriari, S., Bagherinia, M. S. and Edalat, P., (2016), A green power supply method for offshore oil and gas platforms in order to reduce associated environmental pollutions in Persian Gulf, 18th Marine Industries Conference.

10- Barrera Limón, J. A., (2006), Offshore Wind Farms Connection to Grid, Eindhoven University of Technology.

11- eia, (2017), Natural Gas Intelligence, [Online]. Available: http://www.naturalgasintel.com/.

12- Reiszadeh, M. and Motahar, M., (2011), The wind energy potential in the coasts of Persian Gulf used in design and analysis of a horizontal axis wind turbine, World Renewable Energy Congress, pp. 4058-4065.

https://doi.org/10.3384/ecp110574058

13- Wind Turbine SWT-3.6-120 Technical specifications, (2016), Siemens AG, Germany.

14- Multon, B., (2012), Marine Renewable Energy Handbook. London: John Wiley \& Sons, Inc.

https://doi.org/10.1002/9781118603185

15- Public Organizational Announcement of Ministry of Energy, Tehran, 95/14273/30/100.

16- Mone, C., Stehly, T., Maples, B. and Settle, E., (2015), 2014 Cost of Wind Energy Review, Denver.

https://doi.org/10.2172/1225925 